\title{
Contemplación estética vs. mirada fenomenológica: una mirada a la estética fenomenológica y a la fenomenología del arte en Edmund Husserl*
}

Román Alejandro Chávez Báez**

Universidad Iberoamericana, México D.F.

Recibido: 12 de diciembre de 2009 Aprobado: 30 de enero de 2010

A través de una reconstrucción de los pasajes epistolares y de las menciones que en diversas obras (programáticas y de husserliana) hace Husserl sobre el arte, el presente estudio se propone mostrar las claves para una "estética fenomenológica" que asume la reducción fenomenológica como una actitud epistémica análoga a la intuición estética, y a la cual Husserl se refirió como un campo fértil para investigaciones futuras. En este sentido, se asume que el modo de proceder de la fenomenología realiza en cierta forma la contemplación estética.

Palabras clave: Husserl, reducción fenomenológica, intuición estética, arte, genio.

* El presente ensayo forma parte de la investigación de mi tesis doctoral que he venido desarrollando en el Departamento de Filosofía de la Universidad Iberoamericana, México D.F., la cual lleva por título: Arte y fenómeno: hacia una estética fenomenológica y una filosofía del arte en Edmund Husserl.

** Profesor del Departamento de Filosofía de la Universidad Iberoamericana, México D.F. Es miembro asociado del Círculo Latinoamericano de Fenomenología (CLAFEN). Correo electrónico: ralexch74@gmail.com 


\section{Sthetical contemplation vs. Phenomenologic insight:}

An insight to the phenomelogic sthetic and to the phenomenology of art in Edmund Husserl

\section{Abstract}

Through a reconstruction of the fragments from the epistles and the quoting in different works (programmatic and husserlian) makes Husserl about art, the current study intends to show the keys of a "phenomelogical sthetic", that assumes the phenomenological reduction as an analog epistemic attitude to the esthetic intuition, from which Husserl refered as a fertile field for future researches. On this sense, it is assumed that the way of acting from the phenomenology realizes in a certain way the esthetical contemplation.

Key words: Husserl, phenomenologic reduction, esthetical intuition, ars, genius. 


\section{Contemplation esthétique vs. un regard phénoménologique: Un regard sur la esthétique et la phénoménologie de l'art dans Edmund Husserl}

\section{Résumé}

Moyennant une reconstruction des passages épistolaires et des mentions de divers oeuvres ( programatiques et husserliens ) QUE Husserl a fair sur l'art, il se prppose de démontrer les asoprects clés pour arriver à un sthétic phénoménologique qui assume la réduction phénoménologique comme une actitude épistémique analogue à l'intuiton sthétique. Sur ce point Husserl s'est reféféré comme un champoo fertil pour de futurs recherches.Dans ce sens on assume que le modus operandi de la phénoménologie réalise d'une certaine manière la contemplation esthétique.

Mots clés: Husserl, réduction phénoménologique, intuition sthétique, art, génie. 
Sabemos que Husserl mismo declaró que las cuestiones estéticas tenían un especial interés para él y agregaba "...y no meramente para el amigo del arte que hay en mí, sino también para el filósofo y el fenomenólogo" (Husserl, 1994, pp. 133-136). Esta afirmación "peculiar" no ha sido, hasta donde sabemos, comentada y tenida en cuenta. Más bien, lo común es pensar, tal como lo hace notar Milan Uzelac, que:

A menudo se señala que los discípulos de Husserl produjeron importantes trabajos en estética, aunque Husserl mismo no estaba particularmente interesado con los problemas estéticos, por lo que a primera vista puede parecer bastante obvio que uno no puede hablar de "la estética de Husserl"; también a menudo se ha hecho hincapié en que sus obras contienen pocos casos que traten de manera explícita con problemas estéticos (Uzelac, 1998, p. 7. La traducción es mía).

\section{O como afirma Roberto Taioli:}

Las contribuciones de Husserl a la esfera de la estética no son ciertamente sistemáticas y orgánicas y por tanto no pueden ser comprendidas sino dentro de su filosofía entera. En este sentido, la actitud estética como punto de vista sobre el mundo no puede ser separada de la más amplia visión fenomenológica elaborada por Husserl en el curso de su fascinadora aventura intelectual. Husserl no funda una estética fenomenológica [...] pero pone las bases teoréticas porque una estética fenomenológica deviene imaginable y posible (Taioli, 2008. La traducción es mía).

Desde otra perspectiva, menciona Danielle Lories: "En ocasiones se arguye que los escritos de Husserl proporcionan una fuente de inspiración para considerar el arte de hoy" (Lories, 2006, p. 31). O como Said Tawfik, quien considera exclusivamente la aplicación del método fenomenológico al campo de la estética:

No es el propósito de este estudio repensar el método fenomenológico por sí mismo, pero sí considerar la manera en que se aplica al campo de la estética, y poner en evidencia los mayores problemas y los resultados de esa aplicación. En otras palabras, intentaremos repasar las fundaciones metodológicas en las cuales la estética fenomenológica confía cuando se confronta a los fenómenos del arte (Tawfik, 1991, p. 109). 
Y un poco más adelante afirma que:"El campo de la estética, en particular, se ha convertido en una de las zonas más fructíferas en las cuales las semillas del método fenomenológico han sido sembradas" (Tawfik, 1991).

En este estado de la cuestión, nosotros decimos que lo obvio no es que las cuestiones estéticas o artísticas no tuviesen interés para nuestro autor (recordemos que el filósofo moravo se considera a sí mismo "amigo del arte") o como recién vimos con Uzelac, quien llega a decir erróneamente que "Husserl mismo no estaba particularmente interesado con los problemas estéticos", sino que lo obvio es que su "interés fundamental" no fue estético (mas no que no estuviese interesado) y de esto nos percatamos por las pocas alusiones que nuestro autor hace del arte y de temas estéticos en toda su obra. Sea como sea, lo evidente es que, ciertamente, no sistematizó una estética como tal, pero efectivamente, el método fenomenológico elaborado por nuestro autor fue transportado al ámbito de la estética y es inspiración como modelo de análisis de obras de arte.

Ya en otra ocasión, nosotros mismos percibíamos este mismo estado de la cuestión y en aquél momento decíamos:

Así, hay que reconocer que una estética en la obra de Husserl es breve y quizás insuficiente. Esta temática que hoy nos ocupa no es tratada por nuestro autor en forma sistemática y explícita y lo que pretendemos, a manera de ensayo, para esta ocasión, es explicitar y sistematizar una estética en Husserl a grandes rasgos (Chávez, 2006, p. 210).

Y aunque el panorama no ha cambiado mucho desde entonces, continuamos con el mismo empuje y compartimos plenamente las palabras de Milan Uzelac quien afirma desde este mismo contexto y a propósito de Husserl: "(...) todo esto no implica necesariamente que uno no pueda tratar de reconstruir una 'estética inmanente' presente en su trabajo" (Uzelac, 1998, p. 7). Efectivamente, de lo que se trata es de explicitar, sistematizar o"reconstruir una estética inmanente" en el trabajo de Husserl.

Para esta ocasión en particular no vamos a explicitar y sistematizar una estética en Husserl a grandes rasgos, sino que nos detendremos en el análisis de la carta que Husserl escribe y envía a Hoffmansthal el 12 de enero de 
1907, pero también nos apoyaremos en otros textos. Antes de comenzar el análisis, permítaseme notar que en el momento de la carta de Husserl a Hofmannstahl (Husserl, 1994), Husserl estaba ocupado trabajando en el desarrollo de la reducción fenomenológica, que ocupa un lugar fundamental en la evolución de su método fenomenológico.

Husserl comienza agradeciendo a Hofmannstahl por un regalo que recibió durante su reciente visita el 6 de diciembre de 1906 y pasa a discutir sobre fenomenología y arte, lo que revela algunas conexiones estéticas entre una fenomenología pura y el arte puro. Husserl reconoce como puramente estético el arte de Hofmannstahl de imágenes de "estados internos", en una esfera no de "imágenes", sino de "belleza estética". Los estados estéticos son importantes para el fenomenólogo debido a la objetivación. Husserl dibuja un paralelo entre su trabajo de llegar a un sentido lúcido de los problemas básicos de la filosofía, y moviéndose hacia adelante, un método para la solución de estos problemas básicos.

Dejando a un lado la exposición de Husserl sobre la fenomenología, centrémonos en las cuestiones estéticas. Husserl considera que la contemplación estética es similar a la mirada fenomenológica. Bajo esta premisa, se entiende incluso que el proceder artístico es semejante al proceder fenomenológico, pues en ambos se hace a un lado la actitud natural, se desconecta dicha actitud. La intuición estética en el arte puro está estrechamente relacionada con la intuición fenomenológica; sin embargo, esto no debería ser asociado con cualquier tipo de placer estético, debido al hecho de que la fenomenología sólo tiene en cuenta las investigaciones y los fenómenos cognitivos. El fenomenólogo no se refiere a la esfera del arte, sino a la esfera de la filosofía. El artista observa el mundo y el aumento de conocimiento del hombre y la naturaleza de una manera que poco se refiere a cómo el fenomenólogo observa el mundo. Para los fenomenólogos el mundo se hace fenómeno, lo que hace que toda la existencia carezca de importancia. El artista, en cambio, no trata de encontrar el "significado" del fenómeno del mundo y comprender sus conceptos, pero intuitivamente lo que le interesa tiene como fin crear las formas estéticas. 
Posteriormente, Husserl ofrece a Hofmannstahl sus mejores deseos, esperando que en el mundo encuentre el interés para su desarrollo interno y su crecimiento. Tal vez esto era necesario debido al hecho de que Husserl admite ser reacio a comentar la obra de Hofmannstahl, ya que solamente sus observaciones podrían resultar interesantes para el poeta.

Al final de la carta, Husserl siente el deber -de alguna manera- de resumir su orientación entregando en una apostilla de la carta las"reglas de oro" que tienen que inspirar la actitud del artista:

1. Él tendrá genio, de lo contrario no es artista.

2. Deberá guiarse de manera pura y exclusivamente, por su demonio.

3. Observar a todos los demás estética y fenomenológicamente, ya que los demás saben.

Si analizamos estas reglas de oro vemos cómo coincide el pensamiento de Husserl sobre el artista como genio con el de Kant, en el sentido de que el artista no tiene que presentar sus pasos y procedimientos (en esto no es similar al fenomenólogo). Y guiarse por el demonio, nos recuerda al Platón del Banquete cuando nos dice que es el demon de Eros quien otorga sabiduría y será demónico quien se entregue a Eros y éste es el artista (en este punto, no sé si el fenomenólogo será demónico, pero me parece que sí le interesa Eros y la sabiduría). Y en cuanto al tercer punto, me parece que también el fenomenólogo observa al otro.

Lo importante de todo ello es que en dicha carta Husserl menciona que el método fenomenológico es el método de la intuición, entiéndase, del puro mirar. De hecho, los fenómenos son observables sólo “(...) a través del puro mirar, en el puro análisis que mira y en la abstracción" (Husserl, 1994, Dokumente III). Y continúa:

(...) para indagar el conocimiento mirando, yo no puedo atenerme al mero cuasi-conocer verbal (al pensamiento simbólico), sino, que debo atenerme, al auténtico conocer evidente, al conocer que ve, a pesar de que también el conocimiento simbólico en su relación con el conocimiento evidente necesita llevar a cabo un análisis fenomenológico de la esencia (Husserl, 1994, Dokumente III). 
Y ya en materia estética:

La intuición de una obra de arte puramente estética se ejecuta en estricta puesta entre paréntesis de cualquier actitud existencial del intelecto y de cualquier actitud del sentimiento y de la voluntad que como tal presuponga una actitud existencial. $\mathrm{O}$ mejor: la obra de arte nos traslada (a la vez que nos obliga) al estado de la intuición puramente estética que excluye a aquélla actitud [existencial] (Husserl, 2000, p. 62).

Husserl es claro, la intuición estética implica un cambio de actitud en la que se deja a un lado la actitud existencial por medio de una puesta entre paréntesis, esto es, por medio de una epojé que nosotros llamamos estética. Entonces para nuestro autor el intuir fenomenológico y el intuir estético están entre sí emparentados cercanamente, en el sentido de que ambos intencionan la desconexión de toda toma de posición natural, equivalente a la desconexión de toda toma de posición existencial del intelecto, y de toda toma de posición del sentimiento y la voluntad que presupone una toma de posición existencial como tal. Un poco más adelante, dando a entender que hay una similitud entre la intuición estética y el trabajo fenomenológico y éste trabajo al compararlo con la actividad creadora del artista, afirma:"Pues también el método fenomenológico reclama la estricta desconexión de todas las proposiciones existenciales. Ante todo, en la crítica del conocimiento" (Husserl, 2000, p. 63). E insiste nuestro autor:

(...) el mirar fenomenológico es asociado de cerca al mirar estético en el arte "puro"; sólo que, claro está, no es un mirar para gozar estéticamente, sino ante todo para indagar con vistas a conocer y constituir determinaciones científicas de una nueva esfera (la filosófica) (Husserl, 2000, p. 64).

Y enseguida agrega:

El artista que "observa" el mundo para alcanzar desde él, para sus fines, conocimiento de la Naturaleza y del Hombre, se comporta respecto al mundo de forma parecida a como lo hace el fenomenólogo. Es decir: no como un científico o un psicólogo que observa la naturaleza, no como un observador humano práctico [...] Para él, el mundo, al ser observado, se vuelve fenómeno, su existencia le es indiferente, exactamente como para el filósofo (en la crítica de la razón) (Husserl, 2000, p. 64). 
Existe para Husserl un "parentesco muy cercano" entre el intuir fenomenológico y el intuir estético y esto se justifica diciendo que ambas actitudes se desconectan de la toma de posiciones naturales. Sería importante averiguar qué quiere decir lo natural con respecto a ambas actitudes y con ello determinar de modo preciso el sentido del "parentesco cercano" al que alude Husserl y al mismo tiempo, investigar cómo está dado el modo correspondiente de desconexión, pues esto es lo que determinará, correlativamente, el sentido de lo desconectado en cada actitud. Y es que la desconexión de una actitud natural posibilita mostrar fenomenológicamente como apariencia (Schein) lo puesto (das Gesetze) de su posición. Aclararnos la afinidad entre el intuir fenomenológico estético consistirá en poner de manifiesto la apariencia que en cada caso se vuelve visible, su sentido fenomenológico. Mostrar el sentido, correspondiente en cada caso, de apariencia, tiene que ver con su referencia intencional correlativa, ya que el sentido de apariencia se hace visible solamente en el cómo del comportamiento intencional de los actos. En otras palabras, queremos analizar la estructura intencional correlativa que existe en el correspondiente sentido de apariencia que hace visible tanto la actitud fenomenológica como la actitud estética y con ello poner de manifiesto las diferencias entre ambas actitudes.

Como sea, esto quiere decir que para el artista que actúa de forma parecida al fenomenólogo, el mundo se torna fenómeno y la existencia del mundo le es indiferente como al fenomenólogo. Este modo de actuar es para “(...) apropiárselo intuitivamente para abarcar así la plenitud de las configuraciones, materiales para configuraciones creativas estéticas" (Husserl, 2000, p. 64). En la intuición puramente estética el sello del ser o del no-ser, del ser posible o ser probable, etc., queda desconectado, lo que interesa es lo reproducido artísticamente (el objeto-imagen) y en este sentido, se aplica la modificación de la neutralización de la percepción que va acompañada de la epojé estética. Por tanto, podemos decir que la estética fenomenológica y la actividad creadora artística dejan a un lado la actitud natural, la ponen entre paréntesis.

Entonces, para la realización de la estética fenomenológica debemos dejar a un lado la actitud natural y entrar en la actitud estética que es una acti- 
tud fenomenológica. Si Husserl nos ha dicho que el proceder del artista es similar al proceder del fenomenólogo, quizá lo interesante, por ahora, sea revisar cómo es que Husserl considera el proceder artístico. Sabemos que su proceder es similar al proceder del fenomenólogo y lo que haremos es intentar tematizar fenomenológicamente ese proceder artístico. Pero lo verdaderamente importante para nosotros, será enfrentar la contemplación o goce estético con la mirada puramente intuitiva fenomenológica y para ello nos vamos ayudar del mismo Husserl. Ahora bien, tanto la contemplación estética como la mirada fenomenológica son actitudes que remiten a un sujeto desinteresado', pues la epojé, al hacer aparecer la intencionalidad en el objeto, conlleva un desinterés que tiene como finalidad garantizar la intuición originaria de la cosa misma en su aparecer fenoménico. Esto garantiza, pues, la dación del objeto en el darse a sí mismo.

En todo caso, Husserl piensa que "el eco del mundo de la existencia" como incrustación ocultante del mundo-de-la-vida, tiene que ser tenido a distancia: "Cuanto más os repica el eco del mundo de la existencia, cuánto más la obra de arte solicita una toma de posición existencial, un poco como la apariencia" (Husserl, 2000). La epojé abre delante una nueva posibilidad de vida, actúa una conversión ética y gnoseológica que invierte también la esfera estética. Lo bello es, si acaso, el fruto de una abertura que abre delante de nosotros un misterio. ¡Después de la epojé es todo puesto en cuestión, todo

1 "La epojé, en efecto, es una actitud teorética que permite al objeto aparecer en sí, en su ipseidad esencial, sin participación interesada del científico. Se trata aquí del aspecto noemático de la actitud desinteresada del yo en la actitud fenomenológica; por un lado (noético), el sujeto debe desinteresarse de su objeto y describirlo puramente tal como aparece; por otro lado (noemático), debe dejarse al objeto "libre" de manifestarse él mismo en su autenticidad, sin ninguna ingerencia de parte del sujeto en la experiencia de su ipseidad; ninguna cuestión debe ser planteada por el fenomenólogo al objeto; esta ausencia de interrogación dirigida al objeto expresa precisamente el desinterés del fenomenólogo y garantiza la libertad en la autenticidad del objeto, garantiza la donación originaria del objeto, la originalidad de su donación. No hay que entender por esto que la fenomenología no implique ninguna cuestión dirigida al objeto, ni que no ofrezca ninguna respuesta al interés fenomenológico, sino que la cuestión debe surgir por sí misma en la cosa misma. Si el sujeto no plantea cuestión, el objeto no es menos puesto en cuestión por ello. No es el sujeto quien cuestiona, es el objeto mismo el que se vuelve cuestión. Es por esto que la actitud de suspensión es tan importante, no hace falta que el sujeto turbe el aparecer originario de la cosa, no hay que manchar la pureza de la donación originaria de la cosa. Hay que dejarla hablar a ella misma. Es necesario que el sujeto sea desinteresado al máximo, es decir, que se abstenga de todo interés (siempre más o menos intempestivo). Esto representa evidentemente una tensión extraordinaria para el sujeto: suspende su interés teorético natural, pero no por ello deja de querer conocer al objeto filosóficamente. Tensión reflexiva o recogimiento que trata de hacer el silencio en sí para dejar hablar al objeto, tensión contra la naturaleza, puesto que la reacción natural sería precisamente ir hacia el objeto y preguntarle lo que es -abrazarlo como diría Sartre-, tensión fenomenológica en el sentido más fuerte, pues la actitud natural está suspendida pero subsiste un interés teorético; hay que vivir en la epojé un interés teorético que ha surgido ya en la actitud natural" (Muralt, 1963, p. 1992). 
incomprensible, enigmático! El misterio es solamente soluble si nos llevamos sobre su terreno, si consideramos cada conocimiento como discutible y, por consiguiente, si rechazamos cualquier existencia a priori.

Como sea, sin lugar a dudas el artista opera incomparablemente más en la fantasía que en la percepción con la figura o el modelo de su obra. Lo que dice Husserl del geómetra es, a mi entender, válido también para el artista:

(...) tiene que esforzarse para lograr en la fantasía claras intuiciones, de lo que le libran el dibujo y el modelo, pero al dibujar y modelar realmente está ligado, mientras que en la fantasía tiene la incomparable libertad de dar las formas que quiera a las figuras fingidas, de recorrer formas posibles que se modifican unas en otras sin solución de continuidad, en suma, de engendrar un sinnúmero de figuras nuevas; libertad que le abre literalmente el acceso a los espacios de las posibilidades propias de las esencias con sus infinitos horizontes de conocimientos esenciales. Por eso los dibujos siguen normalmente a las construcciones de la fantasía y al puro pensar eidético que se lleva a cabo sobre la base de éstas y sirven principalmente para fijar etapas del proceso ya llevado a cabo con anterioridad y poder representárselo de nuevo con más facilidad. También cuando mirando la figura se "vuelve a pensar", son los nuevos procesos del pensamiento que se agregan procesos de la fantasía -por su base sensible- cuyos resultados fijan las nuevas líneas de la figura (Husserl, 1992, p. 157).

Así pues, el proceder del artista y del fenomenólogo es similar, ya que:

(...) para el fenomenólogo, que se las ha visto con vivencias reducidas y los correlatos esencialmente correspondientes a éstas, no son las cosas en general distintas a las del artista, pues hay infinitas formas fenomenológicas de las esencias (Husserl, 1992, p.157).

Y hablando del fenomenólogo, aclara nuestro autor que

(...) a su libre disposición están sin duda, dándose originariamente, todos los tipos capitales de percepciones y representaciones, como ejemplificaciones perceptivas para una fenomenología de la percepción, de la fantasía, del recuerdo, etc. También dispone en la esfera del darse originariamente, y por regla más general, de ejemplos de juicios, conjeturas, sentimientos, voliciones. 
Pero como se comprende, no de todas las posibles formas especiales, como tampoco dispone el geómetra [en nuestro caso el artista] de dibujos y modelos para las infinitas formas de cuerpos. En todo caso requiere también aquí la libertad en la investigación de las esencias necesariamente el operar en la fantasía (Husserl, 1992, p. 158).

En el caso del artista y del fenomenólogo, se trata de ejercitar ampliamente y en forma variada la fantasía en la libre transformación de sus datos y con ello fecundarla con observaciones posibles en la intuición originaria. Ahora bien, no podemos perder de vista que estos análisis que emprende Husserl giran en torno a la comparación entre fenomenología y geometría. Pero este análisis lo realiza Husserl en el contexto del modo de acceso a la aprehensión de esencias y para ello enfatiza en la importancia de la fantasía. En este sentido, el eidos, la esencia pura, puede ejemplificarse intuitivamente "en meros datos de la fantasía" (Husserl, 2000, p. 23). De este modo, podemos aprehender originariamente una esencia en sí misma no solamente de intuiciones sensibles, sino "(...) igualmente de intuiciones no experimentativas, no aprehensivas de algo existente, antes bien meramente imaginativas" (Husserl, 2000, p. 23). La geometría es utilizada aquí por Husserl, puesto que en todas las ciencias eidéticas y, evidentemente, en la fenomenología misma “(...) pasan a ocupar las representaciones y, para hablar más exactamente, la libre fantasía un puesto preferente frente a las percepciones, incluso en la fenomenología de la percepción misma" (Husserl, 1992, p. 157). Según esto último, la actividad creadora artística, en tanto tiene como base las representaciones de la fantasía y de la imaginación, puede ser considerada como una disciplina eidética. En este sentido, el arte sería para Husserl, sin lugar a dudas, una actividad eidética, y la estética tiene que reconocer esto último. Husserl está al tanto de esto, pues incluso menciona que:

Un extraordinario provecho cabe sacar de lo que nos brinda la historia, en medida mayor aún el arte y en especial la poesía, que sin duda son productos de la imaginación, pero que en lo que respecta a la originalidad de las innovaciones, a la abundancia de los rasgos singulares, a la tupida continuidad de la motivación exceden con mucho a las operaciones de nuestra propia fantasía, y a la vez y gracias a la fuerza sugestiva de los medios de expresión artística se traducen con especial facilidad en fantasías perfectamente claras al percibirlas en la comprensión (Husserl, 1992, p. 158). 
Sea como sea, es claro que para Husserl la "ficción" constituye el elemento vital de la fenomenología, como de toda ciencia eidética; que la ficción es la fuente en donde saca su sustento el conocimiento de las "verdades eternas" (Husserl, 1992, p. 58). En este sentido, la ficción es lo vital de la creación artística. Por ello, dirá Husserl que existen:

(...) razones por las cuales en la fenomenología, como en todas las ciencias eidéticas, pasan a ocupar las representaciones y, para hablar más exactamente, la libre fantasía un puesto preferente frente a las percepciones, incluso en la fenomenología de la percepción misma, aunque excluida la fenomenología de los datos de la sensación (Husserl, 1992, p. 157).

Arte y fenomenología, en cuanto disciplinas de la esencia pura, ignoran toda afirmación sobre la existencia real: "Justo de esto depende el que ficciones claras les brinden bases no sólo tan buenas, sino en gran medida mejores que los datos de la percepción y experiencia actual" (Husserl, 1992, p. 182).

La contemplación estética o goce estético es un contemplar con goce desinteresado y es un hecho que ilustra la modificación que neutraliza la percepción simple y posicional de la actitud natural. De algún modo es reductiva y esto quiere decir que, en el fondo, se pone en práctica una epojé de corte estética. La contemplación estética "neutra" se parece a la mirada pura del fenomenólogo. Quizá, de algún modo, la contemplación neutra y desinteresada del fenomenólogo tiene un modo estético, pues en la neutralización de la percepción entramos al ámbito de la ficción; se trata del "como-si" (Als-ob) de la fantasía, de una cuasi-realidad. Husserl establece de este modo una relación interesante entre la neutralización y la contemplación estética, en tanto se ocupa de la relación entre fantasía y neutralización.

Una ciencia de la estética se constituye por tanto, preliminarmente, en el fundamento de un "puro" mirar que tiene a la base una eliminación del hombre de mundo y una vuelta a los puros fenómenos. Husserl está claro sobre este punto: el ver fenomenológico es conectado estrechamente al ver estético, no en el sentido en que cada ver fenomenológico sea siempre un ver estético constituyente así de una identidad y una coincidencia; el puro ver no tiene tampoco como fin el así llamado placer estético arraigado 
en una percepción. El goce estético es una manifestación del mundo por medio de una afectividad sensible, pero para que exista el goce estético es necesario que la obra de arte sea una imagen, esto es, que no pierda su carácter representativo, una irrealidad que se contrapone a la realidad objetiva de la actitud natural. Para ello, es necesaria la neutralización que ejecuta la conciencia; mediante dicha neutralización la mera cosa material puede tornarse imagen estética. La fantasía y la imaginación desempeñan un papel fundamental en esta actividad neutralizadora de la conciencia que da origen al goce estético. Así pues, lo estético presupone una aprehensión intuitiva del objeto de la imagen y el goce estético se establece en la manera de representar el objeto en la imagen. En otros términos, esto quiere decir que la obra de arte solicita, por decirlo así, la sensibilidad del artista y del espectador estético, puesto que la cosa material objetiva en su estructura estética que llamamos obra de arte exige que sea considerada o vista como obra, como también debido a que la obra determina lo estético mismo en el espectador y con ello el goce estético.

De nuevo, esto quiere decir que el goce estético se apoya en nuestro encuentro primario e intuitivo con el mundo sensible. El goce estético no se opone a la experiencia sensible del mundo; de hecho, el goce estético es goce de nuestra experiencia sensible y originaria del mundo. En este sentido, hay continuidad entre la sensibilidad en un sentido amplio y la sensibilidad intensa estética. Una cosa es la sensibilidad de colores y otra cosa es la sensibilidad artística que implica una conciencia y juicio axiológico e incluso una afección emotiva. Sin embargo, la experiencia sensible originaria siempre va acompañada de un goce estético. De alguna manera, el goce estético es posterior al goce inmediato que el sujeto experimenta en su manera de representar sensiblemente el mundo. El goce estético acontece originariamente en una sensibilidad subjetiva. En este sentido, experimentamos el mundo en la medida en que somos sensibles. La sensibilidad es la condición de experiencia perceptiva del mundo en sentido amplio, pero también es la condición de la sensibilidad estética de las obras de arte, puesto que el goce estético se arraiga en nuestra experiencia sensible del mundo.

La experiencia estética cumple las potencialidades de la percepción de un modo intenso. Recordemos que preliminar a la actitud estética es la suspen- 
sión de cada posición sobre lo existente. La epojé permite la neutralización y liberación de los presupuestos naturalistas y objetivistas cuya permanencia impide, como enredados en una red, la vista al desnudo del mundo de la vida. Como en la filosofía, también en la estética obra la reducción fenomenológica y el artista en eso no se distingue del filósofo, ambos tienen en común "una íntima afinidad", una proximidad ideal. La experiencia del mundo hecha posible por la epojé es para el artista no el movimiento del concepto que fija el sentido de los fenómenos, él quiere "adaptarle" intuitivamente de ello a los objetivos de una representación estético-creativa. La obra de arte puramente estética es una manifestación de sentido que prescinde de cada posible forma de influencia del intelecto o la voluntad, como centrada de algún modo negativo de su pureza.

La actitud estética, al igual que la actitud fenomenológica, desconecta toda la corriente de la vida mundana, pero en el caso estético, se invita a la constitución del mundo estético que es puramente sensible. El mundo estético ya no es objeto de un conocimiento temático, algo que afecta la esfera del sentimiento. Más bien la sensibilidad estética rompe con el mundo de la sensibilidad cotidiana y nos coloca delante de un objeto estético. Esto quiere decir que la aprehensión estética de la obra de arte implica una ruptura con el mundo de la percepción, ruptura que se deja ver como neutralización. En este sentido, constatamos que el goce estético no es posible sin el fundamento de la modificación de neutralización de los datos de la percepción, que de algún modo son los cimientos materiales de la obra de arte. En la carta no sólo hemos encontrado una fugaz seña, sino una cuestión en cambio bastante relevante. Hemos visto cómo parar Husserl, sólo con la reducción fenomenológica se hace posible acceder a un puro ver libre de presupuestos indagados y no fundados de orden psicologístico y naturalístico. En esta perspectiva, el placer estético no puede darse como mera satisfacción sensible ni como interior movimiento del ánimo. Husserl ve por tanto en el objeto estético una constitución no compleja meramente atribuible a la base sensible-material que, no obstante, constituye de ello la envoltura, por decirlo así. El objeto estético se constituye en su complejidad cuando la objetualidad es alcanzada por el placer estético, que no puede, sin embargo, ser relegado a lo subjetivo. Así pues, la obra de arte es una conexión de representaciones que suscitan un placer estético. 
Entonces hay una neutralización de la posición existencial del soporte material de la obra de arte. Esto implica un dirigir la mirada hacia algún fragmento del objeto percibido, pero la estética como tal acontece como aprehensión de la unidad sensible de la obra misma, la cual es una composición de elementos sensibles finamente separados entre sí. La obra es una unidad que puede concretizarse mediante intuiciones sensibles o perceptivas.

Finalicemos diciendo que el sentido es un problema clave en una estética fenomenológica. Las obras de arte exigen al espectador una forma de acercarse a ellas, ya sea en la contemplación, en el goce, el deleite o el sumergimiento. Desde luego, los objetos artísticos no son cualesquiera tipos de objetos, son objetos que atraen de un modo especial, pues consideramos que en la obra de arte hay un plus que trastorna todo mi ser, mi sensibilidad, mi emotividad, mi pensamiento, mi comprensión. ¿Cómo determinar ese plus de la obra de arte que me fascina? ¿Qué es? Esta pregunta no es de fácil respuesta, y sin embargo hay un "algo" que me atrae.

La obra de arte, en tanto obra, no debe perder su carácter de obra. Esto significa no solamente que el arte expresa o significa ya sea un sentimiento, una idea o inclusive todo un pensamiento. El arte produce algo en mí, obra algo en mí. Lo artístico toma cuerpo en mí. Eso que el objeto artístico obra, en tanto no sea contemplado, se mantiene en posibilidad y sólo se actualiza (obra propiamente) en tanto yo lo contemplo en actitud estética, emotiva. Es esto, lo expresivo, lo que produce, lo que obra, lo que distingue al objeto artístico de los demás objetos, sean éstos naturales o técnicos. De algún modo, es esto que hemos resaltado lo que constituye históricamente la noción de arte.

En este punto podemos abordar la relación entre arte y fenómeno, cuestión que ahora se reviste de gran importancia en nuestra investigación. El arte, sin lugar a dudas, posee un carácter cósico. Es una cosa material que posee una estructura estética (sensible) y con ello diversas texturas. Ahora bien, en la actitud o contemplación estética, a la cual podemos acceder por una epojé estética, esto material queda desconectado, suspendido, neutralizado. La epojé estética tiene una función análoga a la epojé fenomenológica. Recordemos al respecto que la epojé no es un alejarse de las cosas mismas, sino más bien un modo de acceso a los fenómenos. La epojé fenomenológica 
se aplica al mundo en su totalidad, la posicionalidad existencial, natural y objetiva queda desconectada.

¿Con qué nos quedamos? Con el fenómeno en su aparecer, es decir, con aquello que aparece a la conciencia y eso que aparece, que es vivenciado, puede ser descrito. Ahora bien, la epojé estética puede ser aplicada también al mundo en su totalidad, pero sobre todo es aplicada ante objetos artísticos. Lo que da por resultado de su aplicación metódica es el fenómeno artístico en su aparecer, digamos que ha sido desconectado lo cósico-real de la obra. Pero ¿qué es esto artístico en su aparecer originario a la conciencia? Las realidades exhibidas en la obra o, mejor dicho, las quasi realidades reproducidas de la obra. Esto quiere decir que la obra es algo quasi real en mi conciencia y esto es el arte como fenómeno. Aventurándonos a decir esto mismo en otros términos, podemos sugerir que lo desconectado es lo Körper de la obra, esto es, su cuerpo físico, inerte, sólido, material y nos quedamos con el Leib de la obra, esto es, lo vivo, lo orgánico "como si" lo representado en la obra realmente cobrara vida. En este sentido, afirmamos que lo que hay que ver es la obra y no el objeto.

Esto quiere decir que el arte es una actividad espiritual. La noción de arte incluye creatividad y sobre todo espiritualidad ${ }^{2}$. Para nosotros, en este obrar productor y expresivo reside que sea dado el sentido estético. En otros términos, el arte es el medio por el cual un sentido es puesto ahí delante y obra en el sujeto contemplativo estéticamente. De alguna manera, el sentido estético tiene que ver con la intención del autor y la contemplación del espectador desinteresado. Pero no se identifica con ninguno de los dos polos. Está dado en el entrelazo estético entre ambos. El sentido estético es inmanente y apunta intencionalmente a una trascendencia, se abre, por decirlo así, a una trascendencia intencional en la inmanencia misma. El sentido estético es inmanente al objeto artístico que en tanto objeto para una conciencia es intencional. Pero el sentido lo es también de la experiencia estética del espectador. El sentido es sentido para un espectador estético y el sentido es el sentido de la intencionalidad de la obra de arte (es inmanente a la obra).

2 Véase al respecto el fabuloso texto de Kandinsky que inevitablemente surge ahora en nuestra memoria llamado De lo espiritual en el arte. 
Desde luego que sería pertinente indagar en la postura husserliana sobre el sentido, pero es un tema que aún tenemos pendiente. Pero a propósito de nuestras reflexiones sobre el sentido, debemos mencionar que el sentido es meramente espiritual. Sin embargo, el arte es, de alguna manera, expresión de la naturaleza y creación del espíritu. En el arte se deja ver una dimensión sensible, material, natural, pero también una dimensión espiritual, cultural, histórica. La obra de arte es un objeto cultural, pero es también expresión de la naturaleza. La obra es estructura sensible y sentido anímico. En este sentido, el arte posee una doble dimensión que lo hace ser mediador entre naturaleza y espíritu. El arte pertenece a ambos mundos, es sensible y axiológico, es un híbrido que transforma a la naturaleza y al espíritu. El arte en tanto cosa material, incorpora, por decirlo así, lo material mismo al ámbito de la significación cultural.

\section{Referencias}

Chávez, R. A. (2006). ¿Es posible una estética en Husserl? En Xolocotzi, Á (comp.). Actualidad de Franz Brentano. México: UIA.

Husserl, E. (1992). Ideas relativas a una fenomenología pura y una filosofía fenomenológica. México D.F.: Fondo de Cultura Económica.

Husserl, E. (2000). Fenomenología y filosofía existencial. I Enclaves fundamentales (trad. César Moreno Márquez). Madrid: Síntesis.

Lories, D. (2006). Remarks on Aesthetic Intentionality: Husserl or Kant. International Journal of Philosophical Studies, 14, (1).

Muralt, André. (1963). La ldea de la fenomenología. El ejemplarismo husserliano. México: UNAM - Centro de Estudios Filosóficos.

Taioli, R. (2008). Su una lettera di Husserl a Hofmannsthal sull'estetica. Recuperado el 12 de octubre de 2009 de http://biblioteca-husserliana.com/ wp-content/uploads/2008/03/taioli-estetica.pdf 
Tawfik, S. (1991). "The methodological foundations of phenomenological aesthetics". En A.-T. Tymieniecka (ed.). Analecta Husserliana (vol. XXXVII). Dordrecht / Boston/ London: Kluwer Academic Publishers.

Uzelac, M. (1998). Art and Phenomenology in Edmund Husserl. Axiomathes, (1)(2). 